\title{
LOCAÇÕES DE POÇOS EM AMBIENTE CRISTALINO: DA ANÁLISE ESTRUTURAL AOS DADOS DE ELETRORESISTIVIDADE. ESTUDO DE CASO NOS MUNICÍPIOS DE SÃO GONÇALO DO AMARANTE E ARATUBA, CEARÁ.
}

Rafael Mapurunga Saraiva ${ }^{1}$; Cristian Dikson Araujo da Silva ${ }^{1}$; Luizin Henrique Dias Lisboa ${ }^{2}$

Resumo. O presente trabalho refere-se ao estudo geológico/geofísico direcionados a locações de poços profundos em ambiente cristalino ou de rocha dura. Para tal, foram utilizadas uma extensiva analise estrutural, desenvolvida através de imagens de sensores remotos, e o método geofísico elétrico, com a técnica de caminhamento elétrico, em dois municípios no estado de Ceará. O método geofísico aplicado com a análise estrutural respondeu de maneira satisfatória, na maioria dos casos, mostrando um porcentagem de acerto de cerca de 80\%. A metodologia desenvolvida, mostra de maneira clara a importância de um estudo sistemático, visando o aumento significativo da porcentagem de poços com água.

\begin{abstract}
This work refers to the geological / geophysical study directed to locations deep wells in crystalline environment or hard rock. For this, we used an extensive structural analysis, developed through remote sensor images and electrical geophysical method with the resistivity technique in two counties, in the state of Ceará. The geophysical method applied to the structural analysis responded satisfactorily, in most cases, showing a percentage of hit about $80 \%$. The methodology developed, shows clearly the importance of a systematic study, targeting the significant increase in the percentage of wells with water.
\end{abstract}

Palavra chave: Analise estrutural, Geofísica; Caminhamento Elétrico, Locação de Poços.

\footnotetext{
${ }^{1}$ Universidade Federal do Ceará - Departamento de Geologia. Campus do Pici, Bloco 912, CEP - 60455-760, Fortaleza/CE

rafamirv@hotmail.com; cristiandikson@gmail.com;

${ }^{2}$ SEVGEO - SERVIÇOS GEOLÓGICOS. Rua 122, n¹43, Conjunto Tupamirim, Fortaleza, Ceará, CEP: 60744600.

henriquegeo.lisboa@gmail.com.
} 


\section{1 - INTRODUÇÃO}

Não é novidade que o Brasil está passando por uma crise hídrica. Desde 2012 acontece uma redução dos índices pluviométricos, principalmente quando se trata da região Nordeste. No Nordeste predomina o clima semi-árido que é caracterizado por um regime de chuva concentrado em quatro meses, de fevereiro a maio, e uma grande variabilidade nos outros meses. Devido esse grande período de estiagem, muitos açudes e rios encontram-se atualmente secos.

No Ceará, especificamente, muitas famílias estão sendo abastecidas apenas por caminhões pipas, armazenando a água em cisternas. Contudo, o número de recargas que os caminhões fazem para cada família encontra-se diminuindo, muito devido o fato da fonte onde os caminhões capitam a água (açudes e rios) também estarem se esgotando.

Uma das medidas adota pelo Governo do Ceará é a perfuração de poços profundos para o abastecimento das comunidades afetadas pela seca. Em 2015 foram perfurados quase mil poços em números oficias do governo, sem contar os perfurados em terrenos particulares. Segundo dados da SOHIDRA (Superintendência de Obras Hidráulicas do Ceará) cerca de 30\% dos poços perfurados no Ceará mostram-se secos.

Tendo em vista que a perfuração de um poço profundo é relativamente onerosa, existe uma preocupação, tanto da parte do setor público quanto das empresas de perfuração, de diminuir o risco do poço seco, através da locação por geofísica. Os dados aqui utilizados é resultado de 21 locações realizadas pela empresa SEVGEO - SERVIÇOS GEOLÓGICOS nos municípios de São Gonçalo e Aratuba, ambos no Ceará (Figura 1).

\section{2 - MATERIAIS E METODOS}

A análise estrutural será abordada de maneira simplificada e usual. Para a pesquisa no cristalino são estudadas as feições estruturais básicas, impressas nas rochas pelos processos geológicos ao logo de milhares de anos, como feições, formas ou tramas. Basicamente, nesse processo são destacadas as feições de linha, tentando separar a sua origem em dúctil ou rúptil. Tal analise é feita em escala apropriada, geralmente 1:25.000 a 1:50.000, através de imagens de satélites específicas e drenagens em escala compatíveis. Os principais produtos de sensores remotos utilizados são: imagens SRTM, imagens Landsat 7 (pan cromática - Banda 8), imagens de alta resolução do Google Earth e, algumas vezes, imagens regionais do Projeto Radam Brasil. Ainda para complementar, quando possível, são utilizadas imagens aerogeofísicas, como a primeira derivada, visando confirmar as estruturas traçadas ou destacar os traços regionais em ambiente geológico "misto", onde há um forte aporte de coberturas sedimentares (Figura 2). Os dados são 
processados dentro do software ArcGis 10.0, onde é possível gerenciar e aplicar diversos filtros para que se chegue ao produto desejado. Com isso, além das estruturas traçadas, é desenvolvido um banco de dados com feições vetorizadas, com atributos específicos. Dependendo da demanda dos trabalhos, a escala de detalhe pode aumentar até para 1:5.000, com o uso de fotos aéreas.

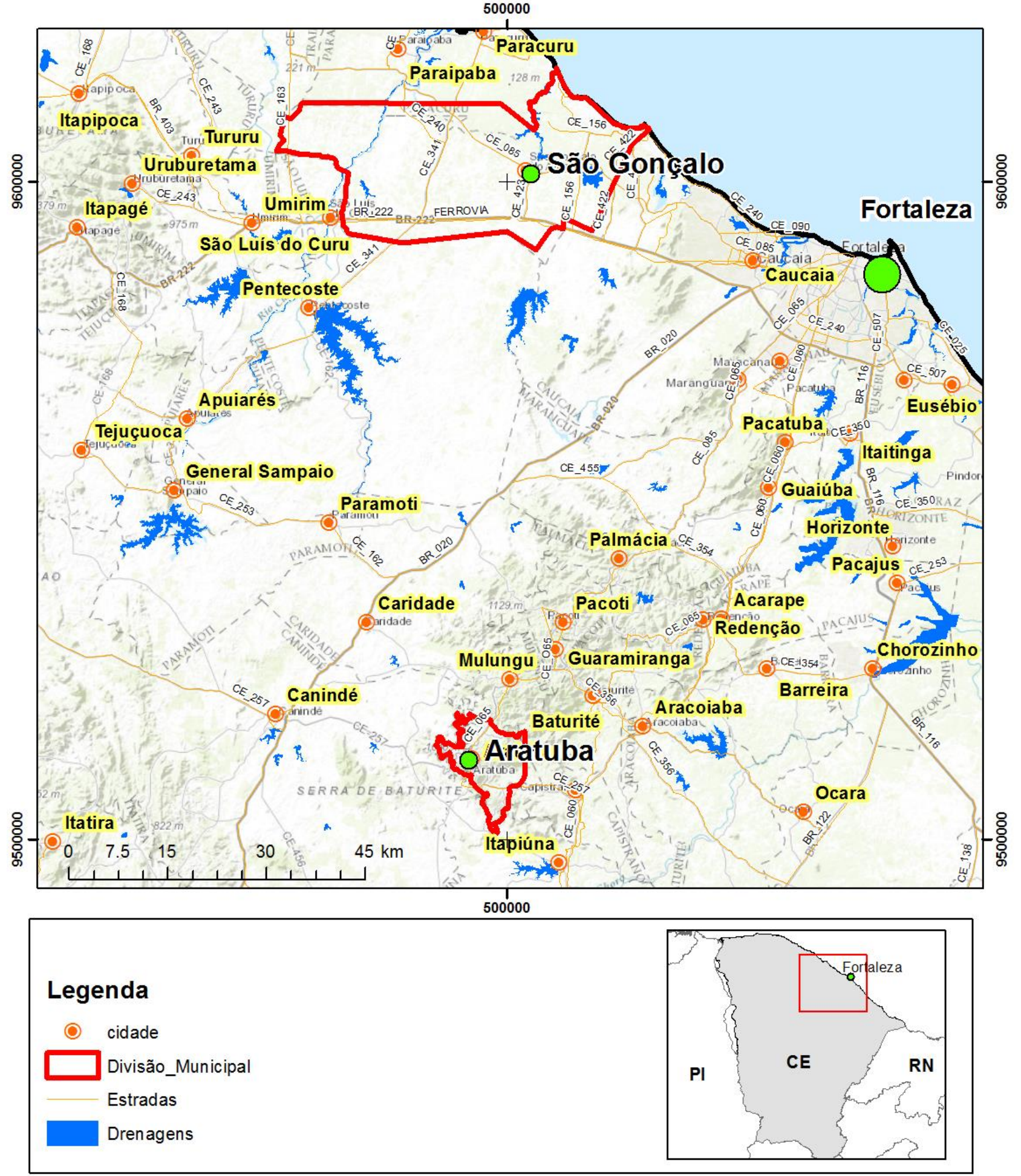

Figura 1: Mapa de localização dos municípios do estado do Ceará onde foram realizados os estudos. 


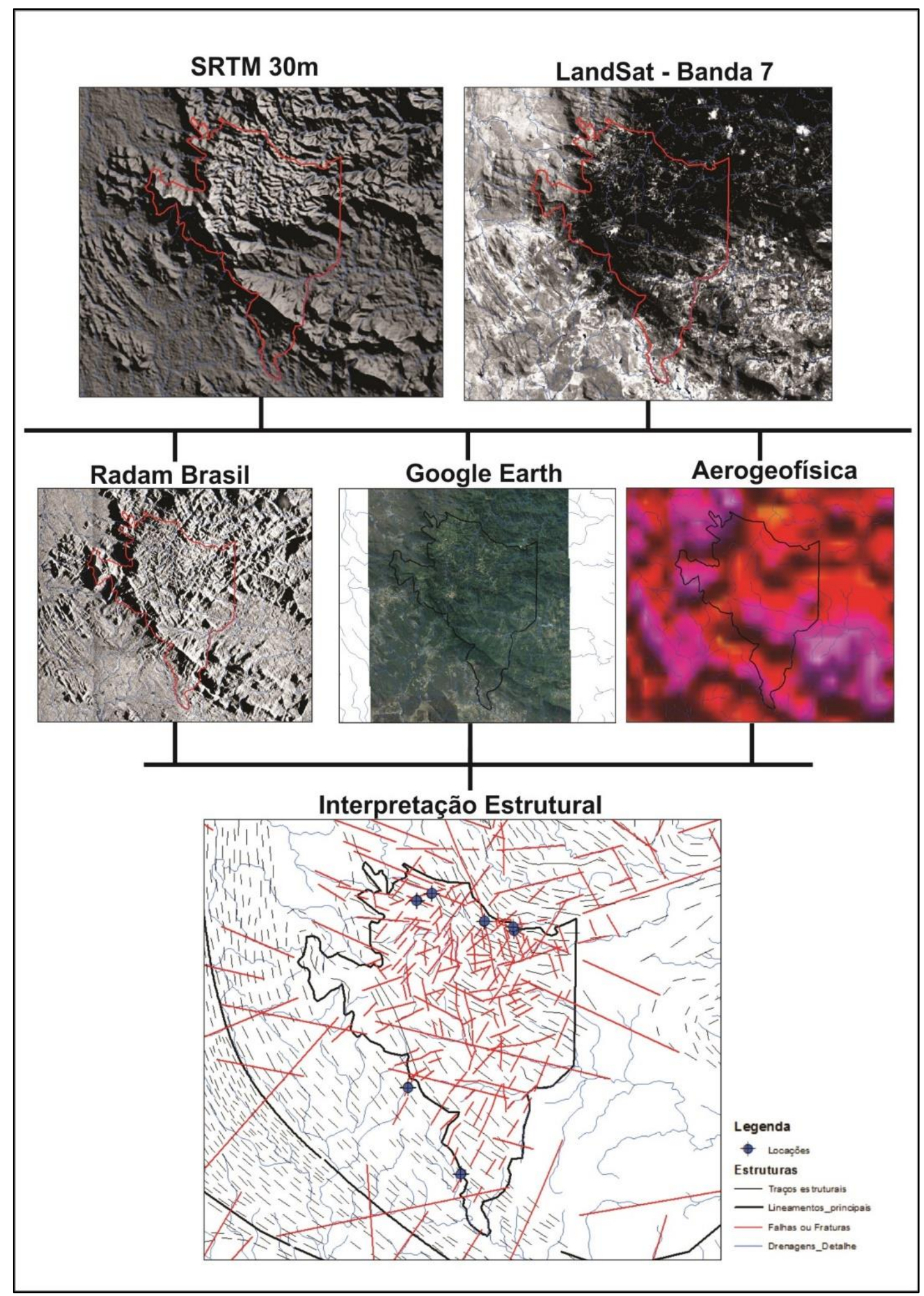

Figura 2: Mosaico de imagens utilizadas para a análise estrutural em Aratuba.

No que se refere ao método geofísico, parte-se das seguintes premissas:

- A eletrorresistividade se dá através da injeção de corrente elétrica no solo, através de eletrodos cravados na superfície do terreno. 
- Variações de resistividade elétrica causadas por heterogeneidades geológicas e hidrogeológicas podem ser medidas e mapeadas.

- As resistividades elétricas das camadas de subsuperfície podem ser calculadas através do espaçamento dos eletrodos, geometria de seus posicionamentos, da corrente elétrica aplicada no solo e das medidas de voltagem.

A eletrorresistividade baseia-se na determinação indireta da resistividade elétrica das rochas e solos, empregando-se a lei de Ohm, cujo princípio consiste basicamente na injeção de uma corrente (I) no solo por intermédio de um par de eletrodos (A e B) e na medida de diferença de potencial $(\Delta \mathrm{V})$ resultante da passagem desta corrente entre outro par de eletrodos ( $\mathrm{M}$ e $\mathrm{N}$ ) (Telford et al., 1976) (Figura 3), onde o valor medido desta diferença de potencial é função da resistividade aparente do subsolo e do arranjo geométrico dos eletrodos, sendo que a profundidade investigada é diretamente proporcional ao espaçamento entre eletrodos (Orellana, 1972). A razão entre voltagem medida e a corrente introduzida no solo é denominada "resistência elétrica" ou "impedância", expressa em Ohms $(\Omega)$.

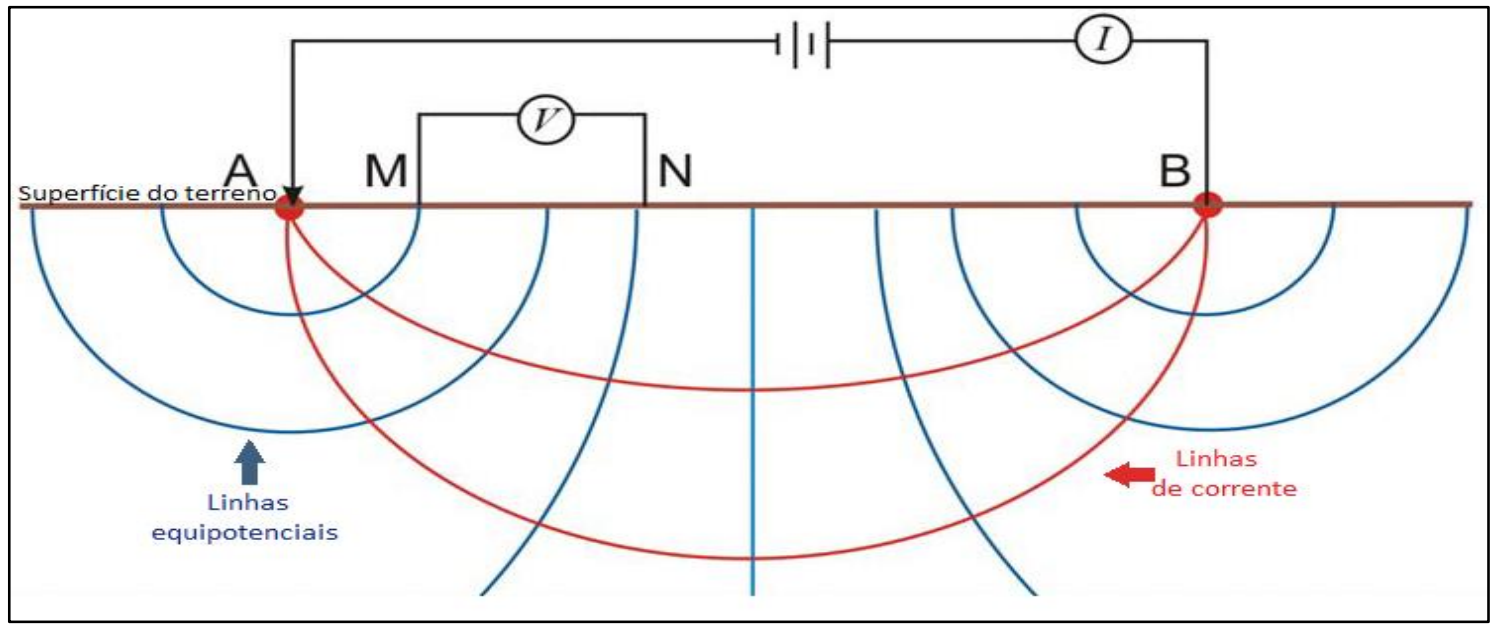

Figura 3:- Princípio do método de eletrorresistividade (Braga, 2007).

Para um terreno heterogêneo e anisotrópico, o valor medido em campo permite calcular a resistividade aparente $\left(\rho_{a}\right)$, expressa pela equação:

$$
\rho_{a}=\frac{\Delta V}{I} K(\text { Eq. 1) }
$$

Onde K é uma constante que depende do arranjo geométrico dos eletrodos, ou seja, está baseada nas distâncias lineares entre os eletrodos de corrente elétrica e potencial. Onde seu valor é dado por:

$$
K=2 \pi\left(\frac{1}{\overline{A M}}-\frac{1}{\overline{B M}}-\frac{1}{\overline{A N}}+\frac{1}{\overline{B N}}\right)^{-1} \text { ou } K=\frac{(A M x A N)}{M N} \pi(\text { Eq. 2) }
$$

A aquisição da resistividade aparente do subsolo pode ser obtida através de três técnicas, com um dos diversos arranjos propostos para o método de Eletrorresistividade (Braga, 2007). Estas técnicas são (Figura 4): Sondagem Elétrica Vertical (SEV), caracterizada pela investigação vertical 
e pontual das variações do parâmetro geoelétricos com a profundidade; Caminhamento Elétrico (CE), que corresponde à investigação lateral das variações do parâmetro geoelétricos em uma ou em várias profundidades e Perfilagem Elétrica (PERF), referente à investigação lateral e vertical das variações do parâmetro geoelétricos efetuadas no interior de furos de sondagens e poços profundos.

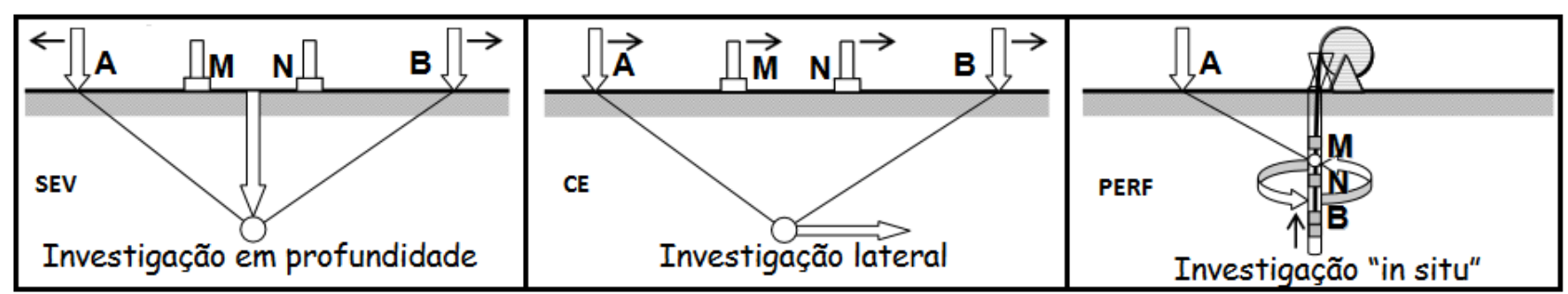

Figura 4: Representação das técnicas referente ao método de Eletrorresistividade (Braga, 2007).

Para a pesquisa os dados de resistividade aparente foram adquiridos através da técnica de CE sendo o arranjo de eletrodos utilizado de Gradiente (Figura 5), que é desenvolvido mantendo-se os eletrodos de corrente (A e B) com uma distância fixa, com uma abertura igual L, com deslocamento apenas dos eletrodos de potencial (M e N) ao longo de uma linha (Orellana, 1972; Ward 1990; Gallas, 2000).

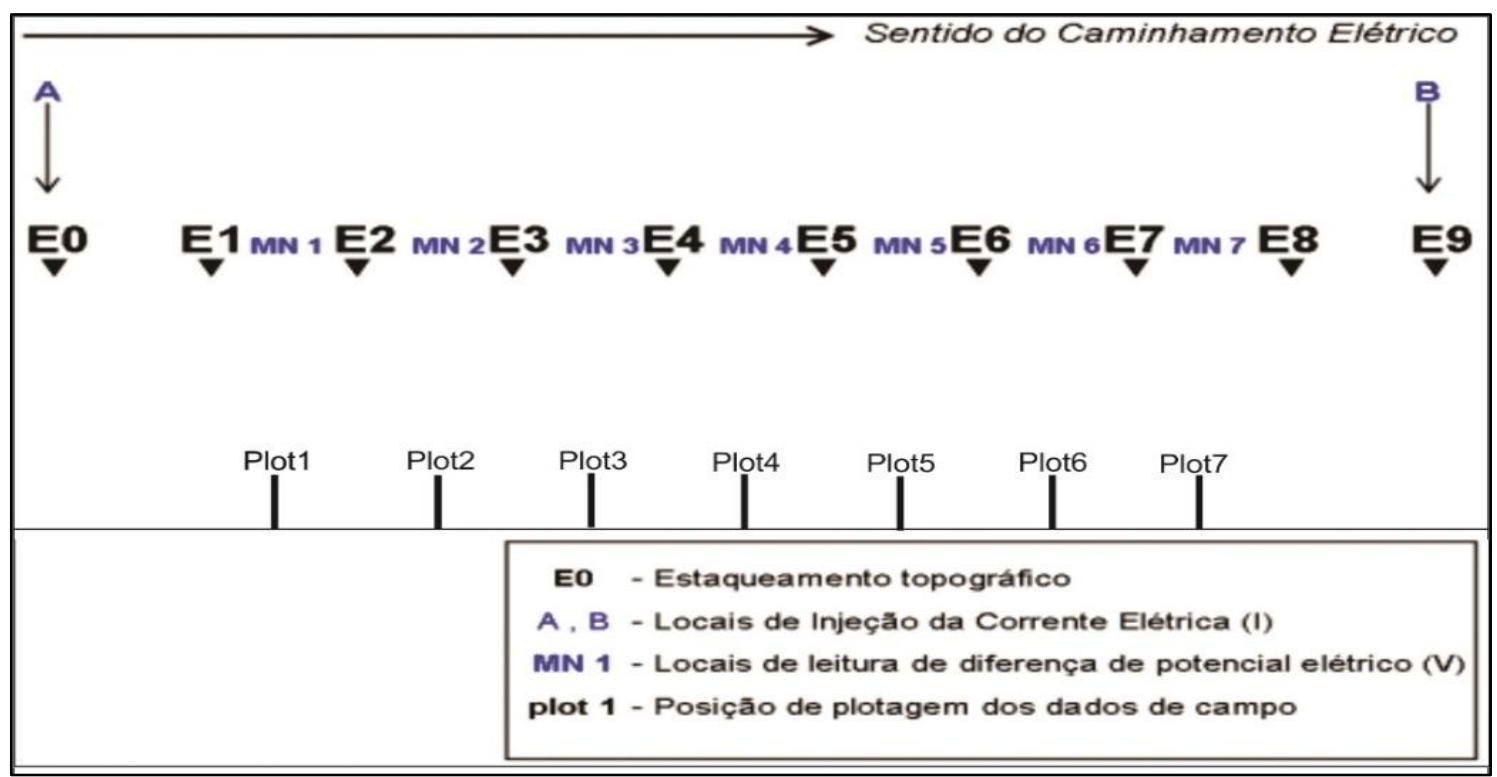

Figura 5: Esquema da técnica de campo do caminhamento elétrico por gradiente (Adaptado de Braga, 2007).

A profundidade de investigação do arranjo Gradiente aumenta com o incremento da abertura $\mathrm{L}$, ou seja, com o aumento do espaçamento de $\mathrm{AB}$, e que a distância entre $\mathrm{M}$ e $\mathrm{N}$ depende do grau de detalhe desejado. Para garantir uma razão sinal/ruído aceitável e preservar a resolução lateral, usualmente emprega-se uma relação $\mathrm{AB} / \mathrm{MN}$ entre 30 e 40. 
Para o cálculo da resistividade aparente utiliza-se a equação 1 sendo a constante geométrico K dado por:

$$
K=\frac{2 \pi}{\overline{M N}}\left(\frac{\cos \alpha}{O A^{2}}+\frac{\cos \beta}{O B^{2}}\right)^{-1} \text { ou } K=\frac{2 \pi}{\left(\frac{1}{A M}-\frac{1}{B M}-\frac{1}{A N}+\frac{1}{B N}\right)}(\text { Eq.3) }
$$

Sendo $\mathrm{O}$ o ponto central de $\mathrm{AB}$ onde os pontos de medidas de potencial situam-se dentro de um retângulo. Segundo Gallas (2000) K muda a cada estação de medidas. Os valores de resistividade aparente podem indicar, qualitativamente, fraturas no embasamento percoladas por águas subterrâneas, através do registro do decréscimo deste parâmetro. O equipamento utilizado foi o Resistivímetro modelo CDC 100012R2A, fabricado pela CTRLTECH (Figura 6).

Em São Gonçalo foram levantados catorze perfis geoelétricos (Figura 7) e em Aratuba foram levantados sete (Figura 8).
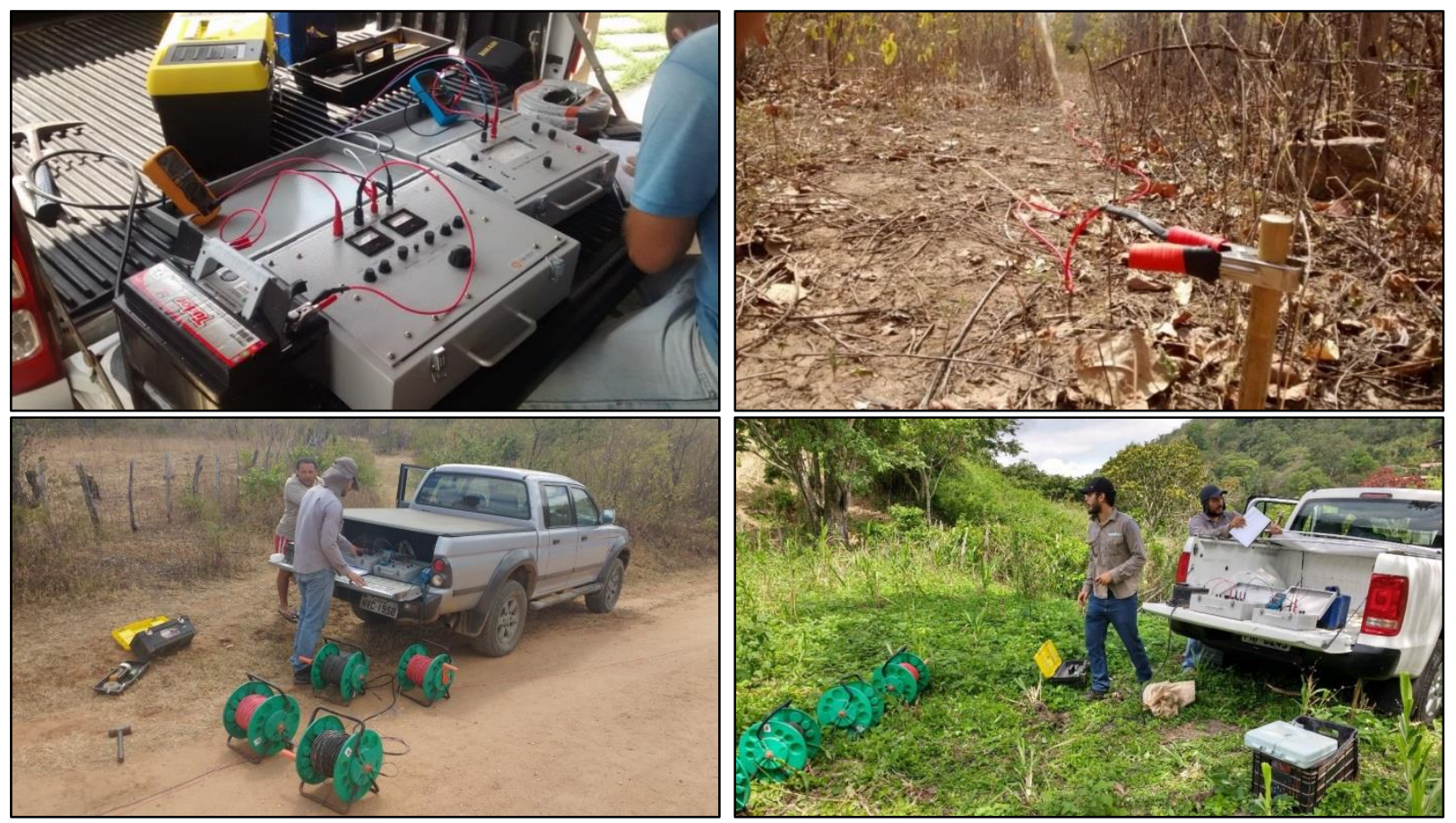

Figura 6: (A) Resistivímetro modelo CDC 100012R2A usado no levantamento. (B) Eletrodos de latão utilizados. (C e D) Parte da logística utilizada durante o levantamento.

\section{ANÁLISE ESTRUTURAL}

Os dois municípios apresentados como exemplos mostram certas peculiaridades, se diferenciando um pouco no quadro geológico. O município de São Gonçalo mostra um ambiente geológico "misto", contendo uma cobertura sedimentar recente, representada pelo grupo barreiras, apresentando, localmente, janelas do embasamento cristalino. Já o município de Aratuba, região serrana, encontra-se inteiramente dentro do contexto cristalino. 
Em São Gonçalo, exibem vários traços, entre eles destaca-se um forte padrão NW-SE e ENESSW, considerados como as principais direções de fraturamento. Em ambos os casos, foi aplicado o modelo clássico de Riedel, onde considera-se a fratura R' como um estrutura potencial/produtora, onde de certa forma, numa interpretação pretérita e ainda em desenvolvimento, considerando os dados existentes de poços, tal fratura seja considerada as de direções NW-SE (Figura 9). Algo interessante destacar, que além dos dados já expostos, ainda são analisados dados geológicos como diques e fraturas (tension gashes), que destacam a entrada de fluidos com preenchimentos ou não para a confirmação de tal afirmação.

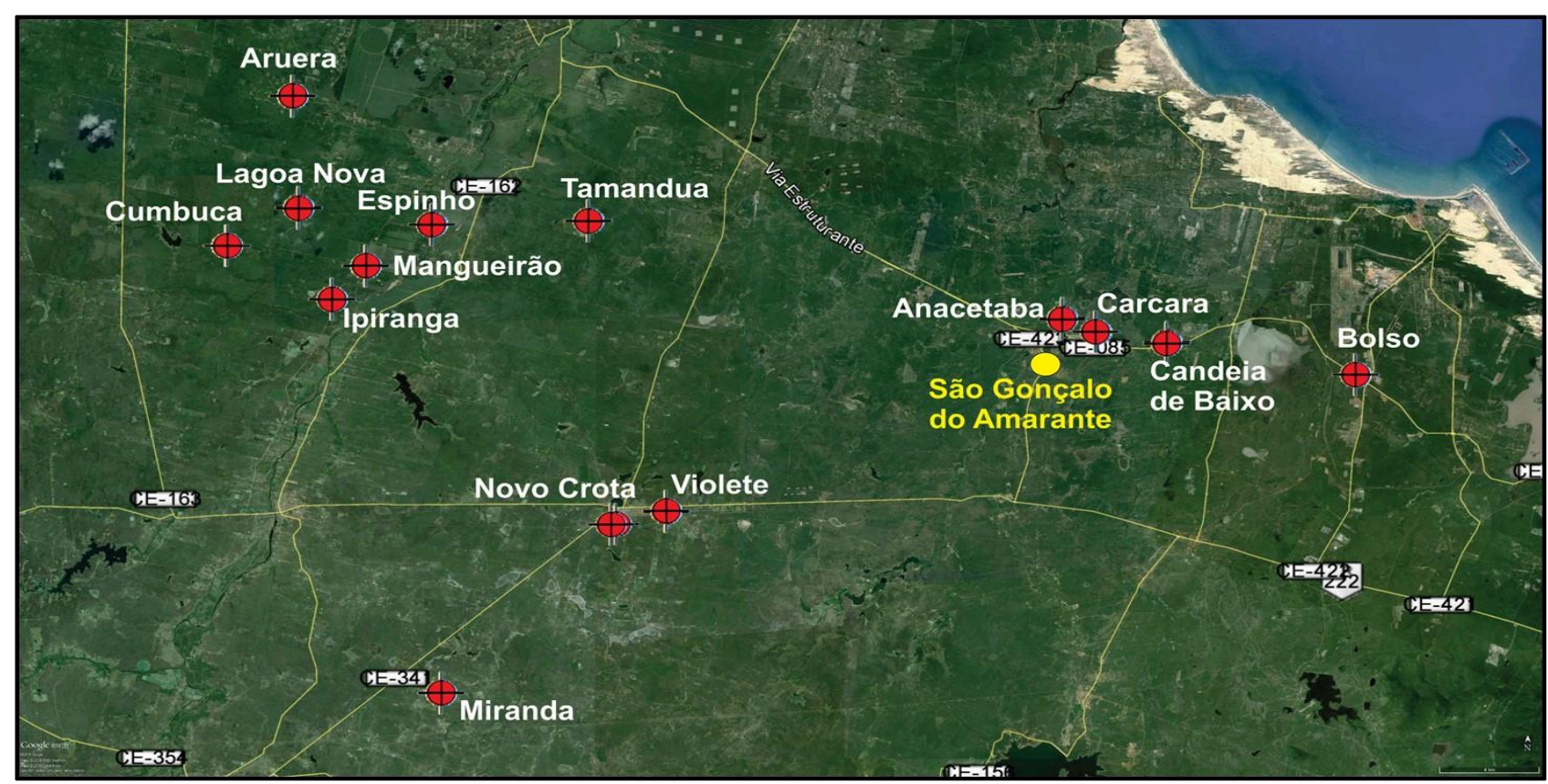

Figura 7: Locações de poços em círculos cruzados na pesquisa em São Gonçalo do Amarante.

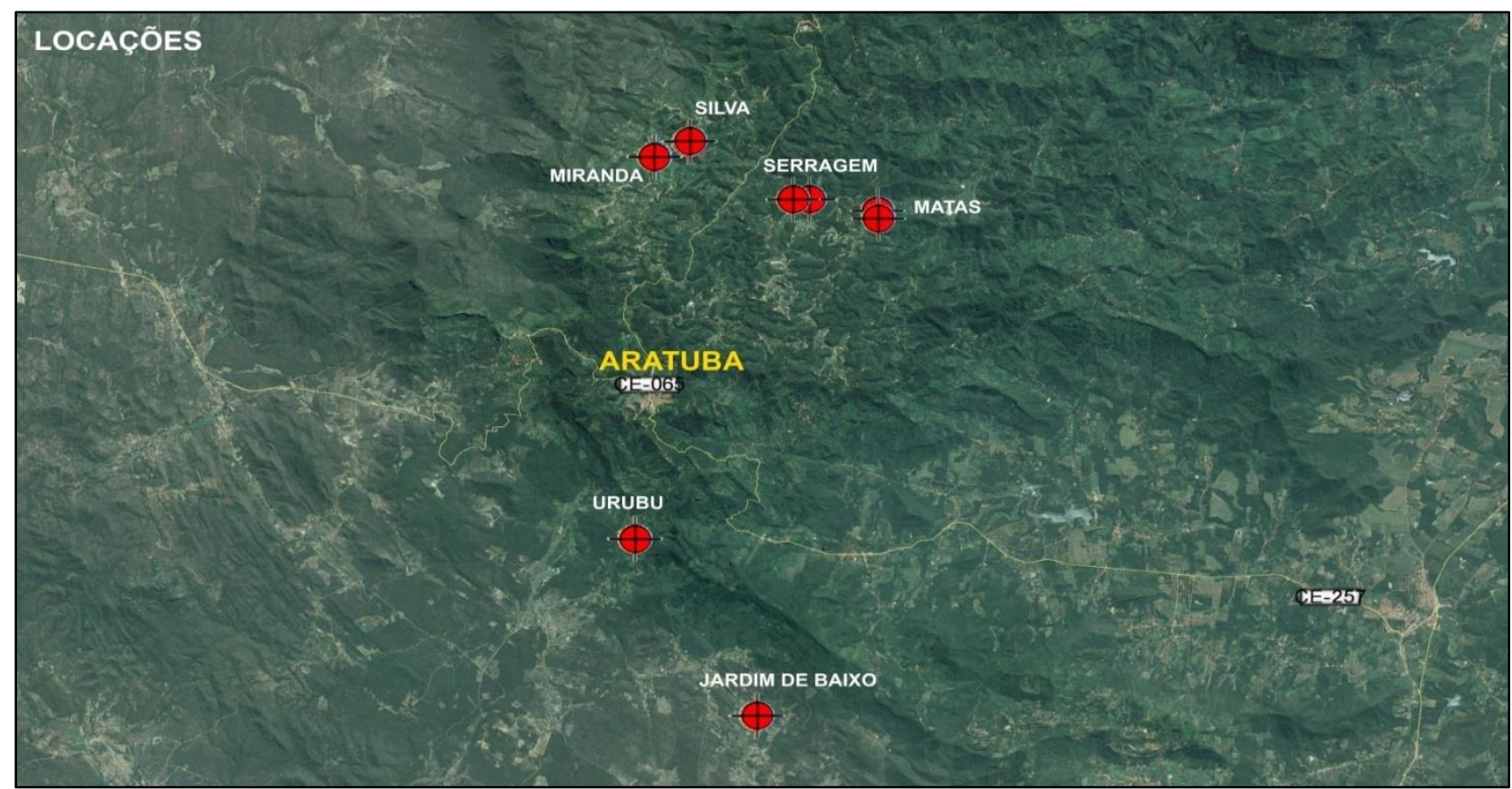

Figura 8: Locações de poços em círculos cruzados na pesquisa de Aratuba. 


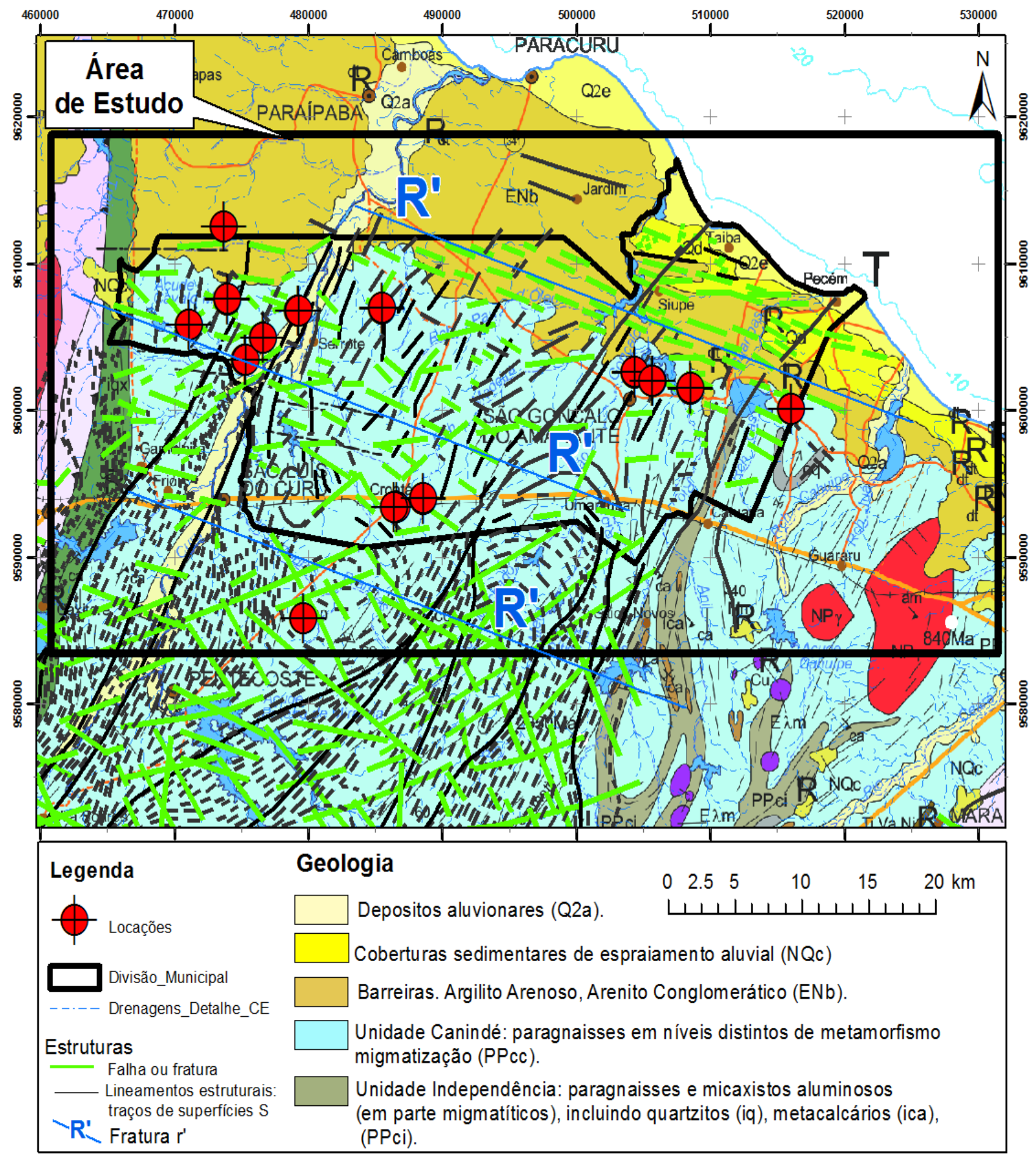

Figura 9: Analise estrutural na região de São Gonçalo. Destacando em azul as estruturas potenciais.

Em Aratuba, através do estudo de padrão de drenagem e imagens de satélites, foi possível traçar as principais estruturas geológicas da área de estudo, onde se observou uma direção principal de fraturamento WNW-ESE e foliações de alto grau metamórfico na direção NW-SE. De modo secundário ocorrem fraturas de direção NE-SW e ENE-WSW (Figura 10). Os perfis geofísicos foram direcionados de acordo com as informações integradas de imagem de satélite e padrão de drenagem. 


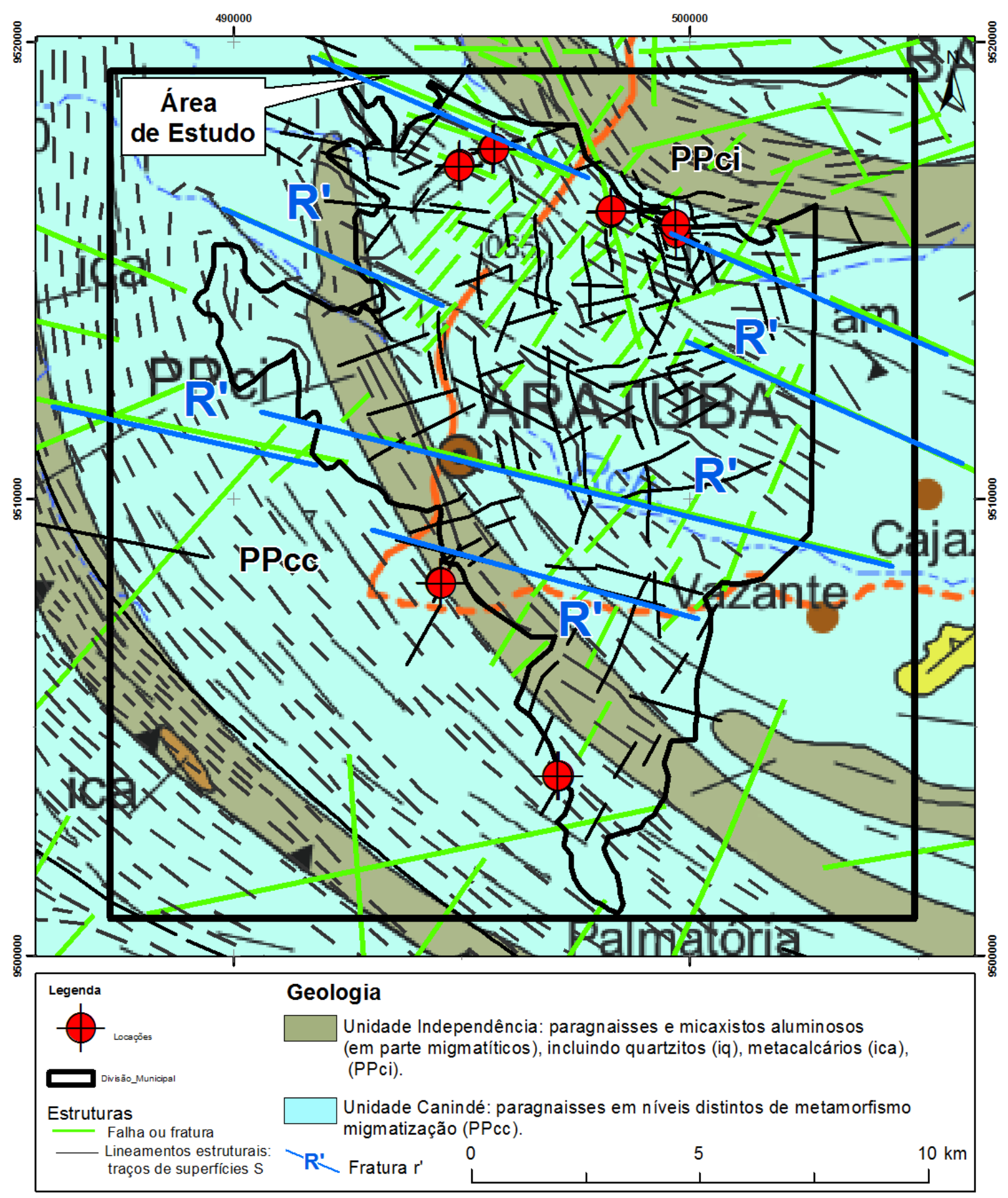

Figura 10: Analise estrutural na região de Aratuba. Destacando em azul as estruturas potenciais.

\section{GEOFÍSICA (ELETRORESISTIVIDADE)}

Quatro perfis característicos foram selecionados para demonstrar a resposta geoelétrica obtida para os municípios de São Gonçalo do Amarante e Aratuba, dois em cada um.

Para a aquisição das resistividades aparente de ambos os municípios foram utilizadas duas aberturas para os eletrodos de corrente $\mathrm{AB}$ para uma melhor acuidade dos dados, uma de $180 \mathrm{~m}$ e outra de $240 \mathrm{~m}$, alcançando profundidades de aproximadamente $50 \mathrm{~m}$ e $70 \mathrm{~m}$, respectivamente, com os eletrodos potenciais $\mathrm{MN}$ espaçados em 6m, respeitando a relação AB/MN entre 30 e 40. 
Os perfis selecionados para o município de São Gonçalo ficam nas localidades de Arueira e Novo Croata. Para o perfil geoelétrico de Arueira optou-se por realizar o levantamento na direção NE-SW perpendicular as principais fraturas identificadas na análise estrutural da região. $\mathrm{O}$ resultado do caminhamento mostrou dois pontos de baixa resistividade aparente de 50,2 e 11,30hm.m para $A B$ de $180 \mathrm{~m}$ (Tabela 1) e de 17 e 70 hm.m para $A B$ de $240 \mathrm{~m}$ (Tabela 2), que podem corresponder a uma descontinuidade potencial. O local indicado para perfuração está indicado na Figura 11. O poço atingiu profundidade de $60 \mathrm{~m}$ com um revestimento de $30 \mathrm{~m}$ e vazão de $8000 \mathrm{~L} / \mathrm{h}$.

Tabela 1: Dados de resistividade com AB de 180m da localidade Arueira, São Gonçalo/CE.

\begin{tabular}{|c|c|c|c|c|c|c|c|c|}
\hline \multicolumn{9}{|c|}{ PERFIL 2 } \\
\hline AB & 180 & & & MN & 6 & & AB/MN & $\mathbf{3 0 a 4 0}$ \\
\hline PROF= & 45 & & & Altura & 0 & & $\mathbf{3 0}$ & \\
\hline ESTAÇÃO & $\mathbf{M}$ & $\mathbf{N}$ & $\mathbf{Y}$ & Leitura $\mathbf{X}(\mathbf{m})$ & $\Delta \mathbf{V}_{\mathbf{1}}(\mathbf{m V})$ & $\mathbf{I}_{\mathbf{1}}(\mathbf{m A})$ & $\boldsymbol{\kappa}$ & $\boldsymbol{\rho}_{\text {f }}(\mathbf{\Omega m})$ \\
\hline 1 & 57,00 & 63,00 & 120,00 & 60 & 12,1 & 240 & 3014,4000 & $\mathbf{1 5 2 , 0}$ \\
\hline 2 & 63,00 & 69,00 & 114,00 & 66 & 9,8 & 240 & 3414,7305 & $\mathbf{1 3 9 , 4}$ \\
\hline 3 & 69,00 & 75,00 & 108,00 & 72 & 4,6 & 240 & 3756,4062 & $\mathbf{7 2 , 0}$ \\
\hline 4 & 75,00 & 81,00 & 102,00 & 78 & 3,0 & 240 & 4018,1853 & $\mathbf{5 0 , 2}$ \\
\hline 5 & 81,00 & 87,00 & 96,00 & 84 & 4,3 & 240 & 4182,8135 & $\mathbf{7 4 , 9}$ \\
\hline 6 & 87,00 & 93,00 & 90,00 & 90 & 10,0 & 240 & 4239,0000 & $\mathbf{1 7 6 , 6}$ \\
\hline 7 & 93,00 & 99,00 & 84,00 & 96 & 14,0 & 240 & 4182,8135 & $\mathbf{2 4 4 , 0}$ \\
\hline 8 & 99,00 & 105,00 & 78,00 & 102 & 10,8 & 240 & 4018,1853 & $\mathbf{1 8 0 , 8}$ \\
\hline 9 & 105,00 & 111,00 & 72,00 & 108 & 9,2 & 240 & 3756,4062 & $\mathbf{1 4 4 , 0}$ \\
\hline 10 & 111,00 & 117,00 & 66,00 & 114 & 3,7 & 240 & 3414,7305 & $\mathbf{5 2 , 6}$ \\
\hline 11 & 117,00 & 123,00 & 60,00 & 120 & 0,9 & 240 & 3014,4000 & $\mathbf{1 1 , 3}$ \\
\hline
\end{tabular}

Tabela 2: Dados de resistividade com AB de 240m da localidade Arueira, São Gonçalo/CE.

\begin{tabular}{|c|c|c|c|c|c|c|c|c|}
\hline \multicolumn{9}{|c|}{ PERFIL 1} \\
\hline$A B$ & 240 & & & MN & 6 & & $A B / M N$ & $30 \mathrm{a} 40$ \\
\hline PROF= & 60 & & & Altura & 0 & & 40 & \\
\hline ESTAÇÃO & $\mathbf{M}$ & $\mathbf{N}$ & $\mathbf{Y}$ & Leitura $X(m)$ & $\Delta \mathrm{V}_{1}(\mathrm{mV})$ & $\mathrm{I}_{1}(\mathrm{~mA})$ & $\kappa$ & $\rho_{f}(\Omega m)$ \\
\hline 1 & 77,00 & 83,00 & 160,00 & 80 & 1,0 & 0 & 5358,9333 & \#DIV/0! \\
\hline 2 & 83,00 & 89,00 & 154,00 & 86 & 7,4 & 240 & 5900,9075 & 181,9 \\
\hline 3 & 89,00 & 95,00 & 148,00 & 92 & 9,3 & 240 & 6389,8592 & 247,6 \\
\hline 4 & 95,00 & 101,00 & 142,00 & 98 & 0,6 & 240 & 6809,0665 & 17,0 \\
\hline 5 & 101,00 & 107,00 & 136,00 & 104 & 0,7 & 260 & 7143,4406 & 19,2 \\
\hline 6 & 107,00 & 113,00 & 130,00 & 110 & 2,8 & 280 & 7380,4437 & 73,8 \\
\hline 7 & 113,00 & 119,00 & 124,00 & 116 & 7,5 & 280 & 7510,9172 & 201,2 \\
\hline 8 & 119,00 & 125,00 & 118,00 & 122 & 9,3 & 280 & 7529,7223 & 250,1 \\
\hline 9 & 125,00 & 131,00 & 112,00 & 128 & 6,4 & 280 & 7436,1128 & 170,0 \\
\hline 10 & 131,00 & 137,00 & 106,00 & 134 & 5,4 & 280 & 7233,7896 & 139,5 \\
\hline 11 & 137,00 & 143,00 & 100,00 & 140 & 2,4 & 280 & 6930,6306 & 59,4 \\
\hline 12 & 143,00 & 149,00 & 94,00 & 146 & 0,3 & 280 & 6538,1320 & 7,0 \\
\hline 13 & 149,00 & 155,00 & 88,00 & 152 & 2,1 & 280 & 6070,6319 & 45,5 \\
\hline 14 & 155,00 & 161,00 & 82,00 & 158 & 6,1 & 280 & 5544,4113 & 120,8 \\
\hline
\end{tabular}




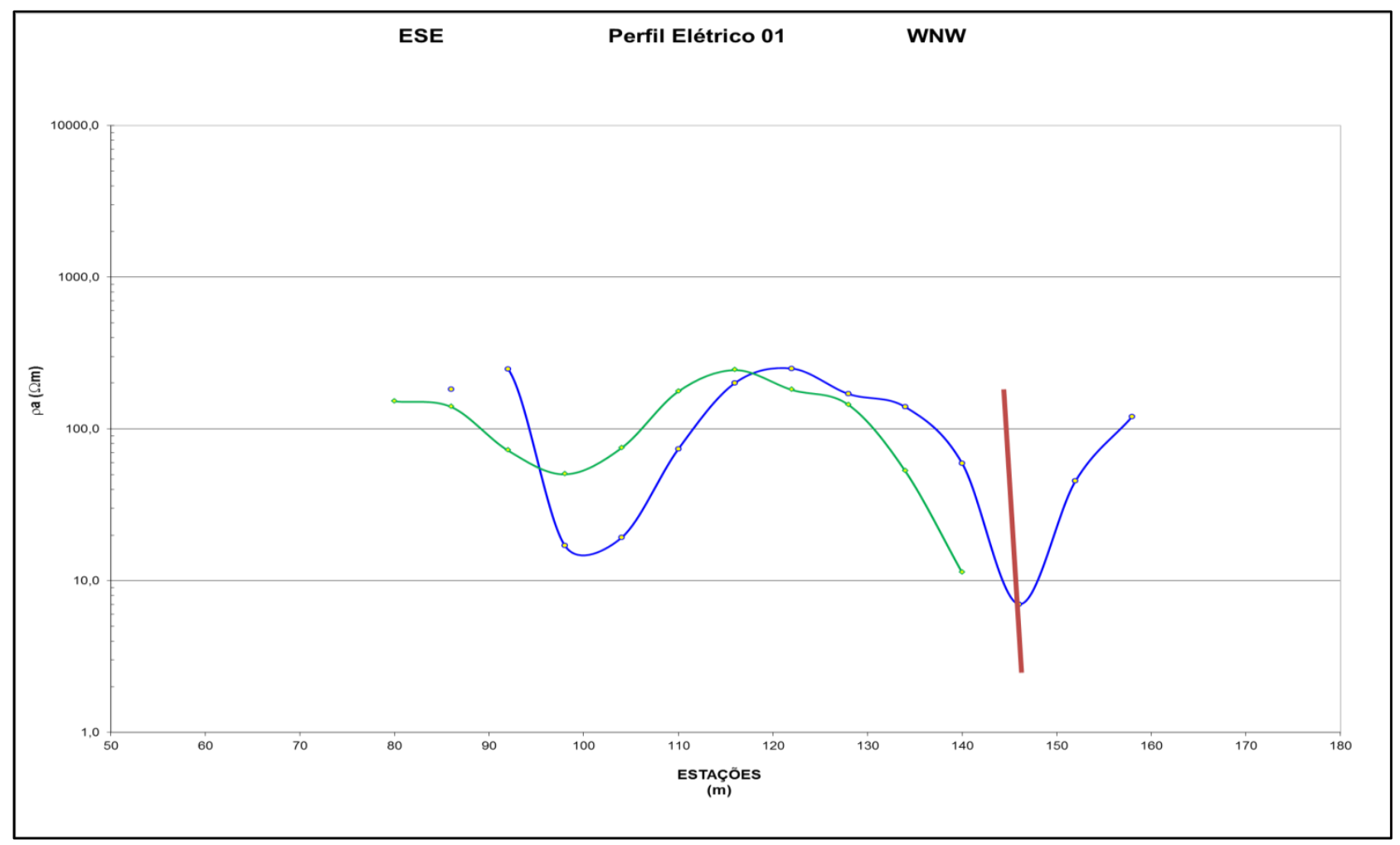

Figura 11: Gráfico com os valores de resistividade plotados. Em verde para AB de 180m e azul para AB de 240m. Destacando em vermelho o local do poço perfurado.

O perfil geoelétrico de Novo Croata foi realizado na direção NE-SW, perpendicular as principais fraturas indentificadas na análise estrutural da região. $\mathrm{O}$ resultado do caminhamento mostrou um ponto condutivo de 12,4 e 14,70hm.m para AB de 180m (Tabela 3) e 240m (Tabela 4) respectivamente. Na Figura 12 pode-se observar p gráfico com os dados de resistividade plotados e a indicação para a perfuração do poço. O poço atingiu profundidade de $50 \mathrm{~m}$ com um revestimento de $30 \mathrm{~m}$ e vazão de $4000 \mathrm{~L} / \mathrm{h}$.

Tabela 3: Dados de resistividade com AB de 180m da localidade Novo Croata, São Gonçalo/CE.

\begin{tabular}{|c|c|c|c|c|c|c|c|c|}
\hline \multicolumn{9}{|c|}{ PERFIL 2} \\
\hline$A B$ & 180 & & & MN & 6 & & $A B / M N$ & $30 \mathrm{a} 40$ \\
\hline PROF= & 45 & & & Altura & 0 & & 30 & \\
\hline ESTAÇÃO & M & $\mathbf{N}$ & $\mathbf{Y}$ & Leitura X (m) & $\Delta V_{1}(m V)$ & $I_{1}(m A)$ & $\kappa$ & $\rho_{\mathrm{f}}(\Omega \mathrm{m})$ \\
\hline 1 & 57,00 & 63,00 & 120,00 & 60 & 5,2 & 520 & 3014,4000 & 30,1 \\
\hline 2 & 63,00 & 69,00 & 114,00 & 66 & 4,3 & 520 & 3414,7305 & 28,2 \\
\hline 3 & 69,00 & 75,00 & 108,00 & 72 & 4,3 & 520 & 3756,4062 & 31,1 \\
\hline 4 & 75,00 & 81,00 & 102,00 & 78 & 1,6 & 520 & 4018,1853 & 12,4 \\
\hline 5 & 81,00 & 87,00 & 96,00 & 84 & 4,2 & 520 & 4182,8135 & 33,8 \\
\hline 6 & 87,00 & 93,00 & 90,00 & 90 & 2,2 & 520 & 4239,0000 & 17,9 \\
\hline 7 & 93,00 & 99,00 & 84,00 & 96 & 2,6 & 520 & 4182,8135 & 20,9 \\
\hline 8 & 99,00 & 105,00 & 78,00 & 102 & 3,0 & 520 & 4018,1853 & 23,2 \\
\hline 9 & 105,00 & 111,00 & 72,00 & 108 & 3,1 & 520 & 3756,4062 & 22,4 \\
\hline 10 & 111,00 & 117,00 & 66,00 & 114 & 3,6 & 520 & 3414,7305 & 23,6 \\
\hline 11 & 117,00 & 123,00 & 60,00 & 120 & 3,8 & 520 & 3014,4000 & 22,0 \\
\hline
\end{tabular}


Tabela 4: Dados de resistividade com AB de 240m da localidade Novo Croata, São Gonçalo/CE.

\begin{tabular}{|c|c|c|c|c|c|c|c|c|}
\hline \multicolumn{9}{|c|}{ PERFIL 1 } \\
\hline AB & 240 & & & MN & 6 & & AB/MN & $\mathbf{3 0 a 4 0}$ \\
\hline PROF $=$ & 60 & & & Altura & 0 & & $\mathbf{4 0}$ & \\
\hline ESTAÇÃO & $\mathbf{M}$ & $\mathbf{N}$ & $\mathbf{Y}$ & Leitura $\mathbf{X}(\mathbf{m})$ & $\Delta \mathbf{V}_{\mathbf{1}}(\mathbf{m V})$ & $\mathbf{I}_{\mathbf{1}}(\mathbf{m A})$ & $\boldsymbol{K}$ & $\boldsymbol{\rho}_{\mathbf{f}}(\mathbf{\Omega m})$ \\
\hline 1 & 77,00 & 83,00 & 160,00 & 80 & 1,0 & 0 & 5358,9333 & \#DIV/0! \\
\hline 2 & 83,00 & 89,00 & 154,00 & 86 & 3,2 & 460 & 5900,9075 & $\mathbf{4 1 , 0}$ \\
\hline 3 & 89,00 & 95,00 & 148,00 & 92 & 2,2 & 460 & 6389,8592 & $\mathbf{3 0 , 6}$ \\
\hline 4 & 95,00 & 101,00 & 142,00 & 98 & 1,9 & 460 & 6809,0665 & $\mathbf{2 8 , 1}$ \\
\hline 5 & 101,00 & 107,00 & 136,00 & 104 & 1,7 & 460 & 7143,4406 & $\mathbf{2 6 , 4}$ \\
\hline 6 & 107,00 & 113,00 & 130,00 & 110 & 2,2 & 460 & 7380,4437 & $\mathbf{3 5 , 3}$ \\
\hline 7 & 113,00 & 119,00 & 124,00 & 116 & 0,9 & 460 & 7510,9172 & $\mathbf{1 4 , 7}$ \\
\hline 8 & 119,00 & 125,00 & 118,00 & 122 & 2,0 & 460 & 7529,7223 & $\mathbf{3 2 , 7}$ \\
\hline 9 & 125,00 & 131,00 & 112,00 & 128 & 1,4 & 460 & 7436,1128 & $\mathbf{2 2 , 6}$ \\
\hline 10 & 131,00 & 137,00 & 106,00 & 134 & 1,5 & 460 & 7233,7896 & $\mathbf{2 3 , 6}$ \\
\hline 11 & 137,00 & 143,00 & 100,00 & 140 & 1,3 & 460 & 6930,6306 & $\mathbf{1 9 , 6}$ \\
\hline 12 & 143,00 & 149,00 & 94,00 & 146 & 2,0 & 460 & 6538,1320 & $\mathbf{2 8 , 4}$ \\
\hline 13 & 149,00 & 155,00 & 88,00 & 152 & 2,1 & 460 & 6070,6319 & $\mathbf{2 7 , 7}$ \\
\hline 14 & 155,00 & 161,00 & 82,00 & 158 & 1,9 & 460 & 5544,4113 & $\mathbf{2 2 , 9}$ \\
\hline
\end{tabular}

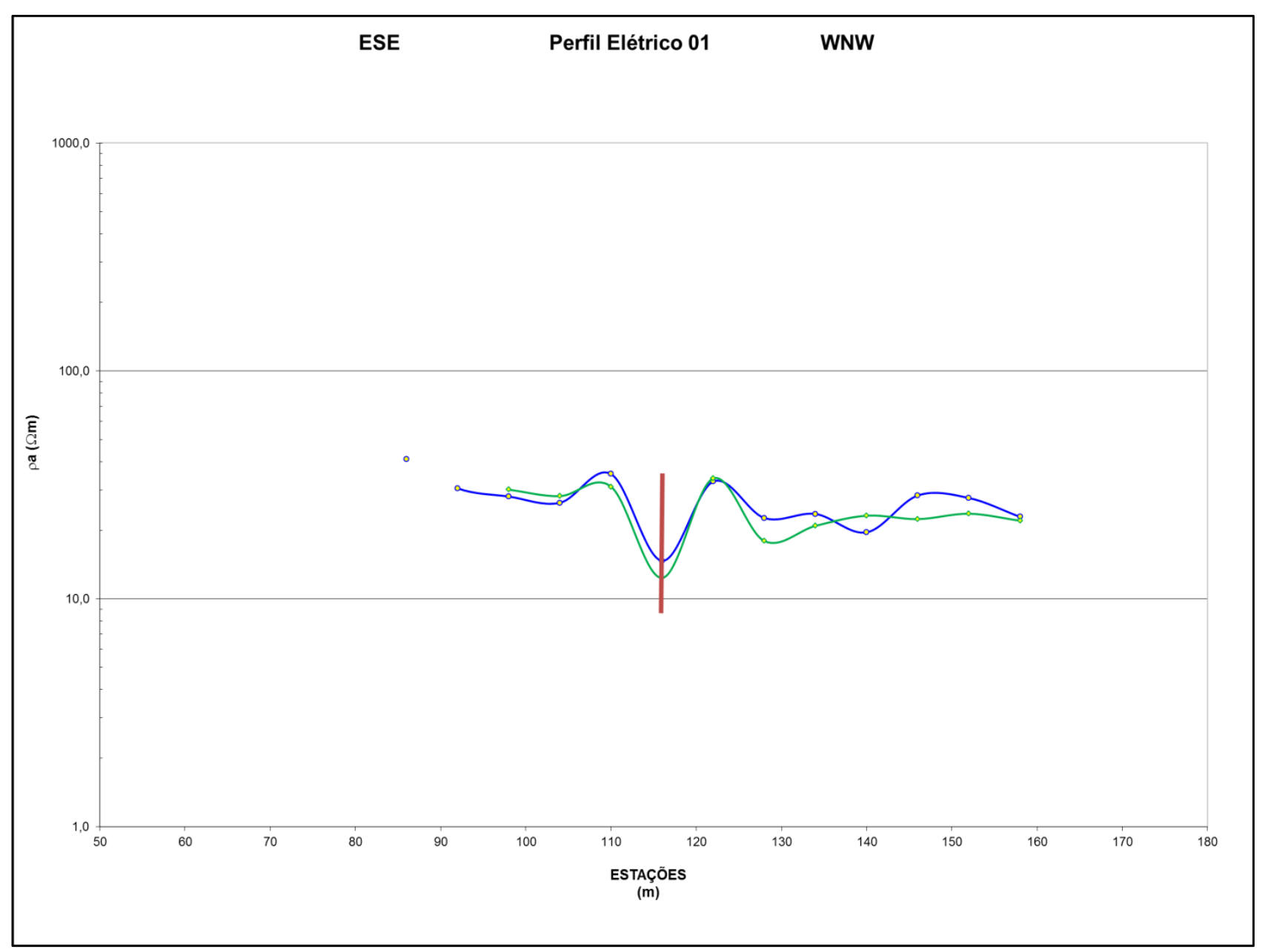

Figura 12: Gráfico com os valores de resistividade plotados. Em verde para $\mathrm{AB}$ de $180 \mathrm{~m}$ e azul para $\mathrm{AB}$ de $240 \mathrm{~m}$. Destacando em vermelho o local do poço perfurado. 
Os perfis selecionados para o município de Aratuba ficam nas localidades de Jardim de Baixo e Serragem. O resultado do caminhamento realizado na direção NW-SE de Jardim de Baixo mostrou dois pontos condutivos de 62 e 98,4Ohm.m para AB de 180m (Tabela 5) e de 63,9 e 87,20hm.m para $\mathrm{AB}$ de $240 \mathrm{~m}$ (Tabela 6), que pode corresponder a uma descontinuidade potencial. O local indicado para perfuração está indicado na Figura 13. O poço atingiu profundidade de $60 \mathrm{~m}$ com um revestimento de $20 \mathrm{~m}$ e vazão de $2500 \mathrm{~L} / \mathrm{h}$.

Tabela 5: Dados de resistividade com AB de 180m da localidade Jardim de Baixo, Aratuba/CE.

\begin{tabular}{|c|c|c|c|c|c|c|c|c|}
\hline \multicolumn{9}{|c|}{ PERFIL 2} \\
\hline$A B$ & 180 & & & MN & 6 & & $A B / M N$ & $30 \mathrm{a} 40$ \\
\hline PROF= & 45 & & & Altura & 0 & & 30 & \\
\hline ESTAÇÃO & $\mathbf{M}$ & $\mathbf{N}$ & $\mathbf{Y}$ & Leitura X (m) & $\Delta \mathrm{V}_{1}(\mathrm{mV})$ & $\mathrm{I}_{1}(\mathrm{~mA})$ & $\kappa$ & $\rho_{\mathrm{f}}(\Omega \mathrm{m})$ \\
\hline 1 & 57,00 & 63,00 & 120,00 & 60 & 12,40 & 400 & 3014,4000 & 93,4 \\
\hline 2 & 63,00 & 69,00 & 114,00 & 66 & 7,60 & 400 & 3414,7305 & 64,9 \\
\hline 3 & 69,00 & 75,00 & 108,00 & 72 & 6,60 & 400 & 3756,4062 & 62,0 \\
\hline 4 & 75,00 & 81,00 & 102,00 & 78 & 8,80 & 400 & 4018,1853 & 88,4 \\
\hline 5 & 81,00 & 87,00 & 96,00 & 84 & 17,10 & 400 & 4182,8135 & 178,8 \\
\hline 6 & 87,00 & 93,00 & 90,00 & 90 & 21,30 & 400 & 4239,0000 & 225,7 \\
\hline 7 & 93,00 & 99,00 & 84,00 & 96 & 9,10 & 400 & 4182,8135 & 95,2 \\
\hline 8 & 99,00 & 105,00 & 78,00 & 102 & 7,10 & 400 & 4018,1853 & 71,3 \\
\hline 9 & 105,00 & 111,00 & 72,00 & 108 & 6,80 & 400 & 3756,4062 & 63,9 \\
\hline 10 & 111,00 & 117,00 & 66,00 & 114 & 9,50 & 400 & 3414,7305 & 81,1 \\
\hline 11 & 117,00 & 123,00 & 60,00 & 120 & 10,00 & 400 & 3014,4000 & 75,4 \\
\hline
\end{tabular}

Tabela 6: Dados de resistividade com AB de 180m da localidade Jardim de Baixo, Aratuba/CE.

\begin{tabular}{|c|c|c|c|c|c|c|c|c|}
\hline \multicolumn{9}{|c|}{ PERFIL 1} \\
\hline $\mathrm{AB}$ & 240 & & & MN & 6 & & $\mathrm{AB} / \mathrm{MN}$ & $30 \mathrm{a} 40$ \\
\hline PROF= & 60 & & & Altura & 0 & & 40 & \\
\hline ESTAÇÃO & $\mathbf{M}$ & $\mathbf{N}$ & $\mathbf{Y}$ & Leitura X (m) & $\Delta \mathrm{V}_{1}(\mathrm{mV})$ & $\mathrm{I}_{1}(\mathrm{~mA})$ & $\kappa$ & $\rho_{\mathrm{f}}(\Omega \mathrm{m})$ \\
\hline 1 & 77,00 & 83,00 & 160,00 & 80 & 0,50 & 30 & 5358,9333 & 89,3 \\
\hline 2 & 83,00 & 89,00 & 154,00 & 86 & 0,50 & 30 & 5900,9075 & 98,3 \\
\hline 3 & 89,00 & 95,00 & 148,00 & 92 & 0,60 & 30 & 6389,8592 & 127,8 \\
\hline 4 & 95,00 & 101,00 & 142,00 & 98 & 0,70 & 30 & 6809,0665 & 158,9 \\
\hline 5 & 101,00 & 107,00 & 136,00 & 104 & 0,40 & 30 & 7143,4406 & 95,2 \\
\hline 6 & 107,00 & 113,00 & 130,00 & 110 & 0,40 & 30 & 7380,4437 & 98,4 \\
\hline 7 & 113,00 & 119,00 & 124,00 & 116 & 0,50 & 30 & 7510,9172 & 125,2 \\
\hline 8 & 119,00 & 125,00 & 118,00 & 122 & 0,90 & 30 & 7529,7223 & 225,9 \\
\hline 9 & 125,00 & 131,00 & 112,00 & 128 & 1,20 & 30 & 7436,1128 & 297,4 \\
\hline 10 & 131,00 & 137,00 & 106,00 & 134 & 0,50 & 30 & 7233,7896 & 120,6 \\
\hline 11 & 137,00 & 143,00 & 100,00 & 140 & 0,40 & 30 & 6930,6306 & 92,4 \\
\hline 12 & 143,00 & 149,00 & 94,00 & 146 & 0,40 & 30 & 6538,1320 & 87,2 \\
\hline 13 & 149,00 & 155,00 & 88,00 & 152 & 0,50 & 30 & 6070,6319 & 101,2 \\
\hline 14 & 155,00 & 161,00 & 82,00 & 158 & 0,50 & 30 & 5544,4113 & 92,4 \\
\hline
\end{tabular}




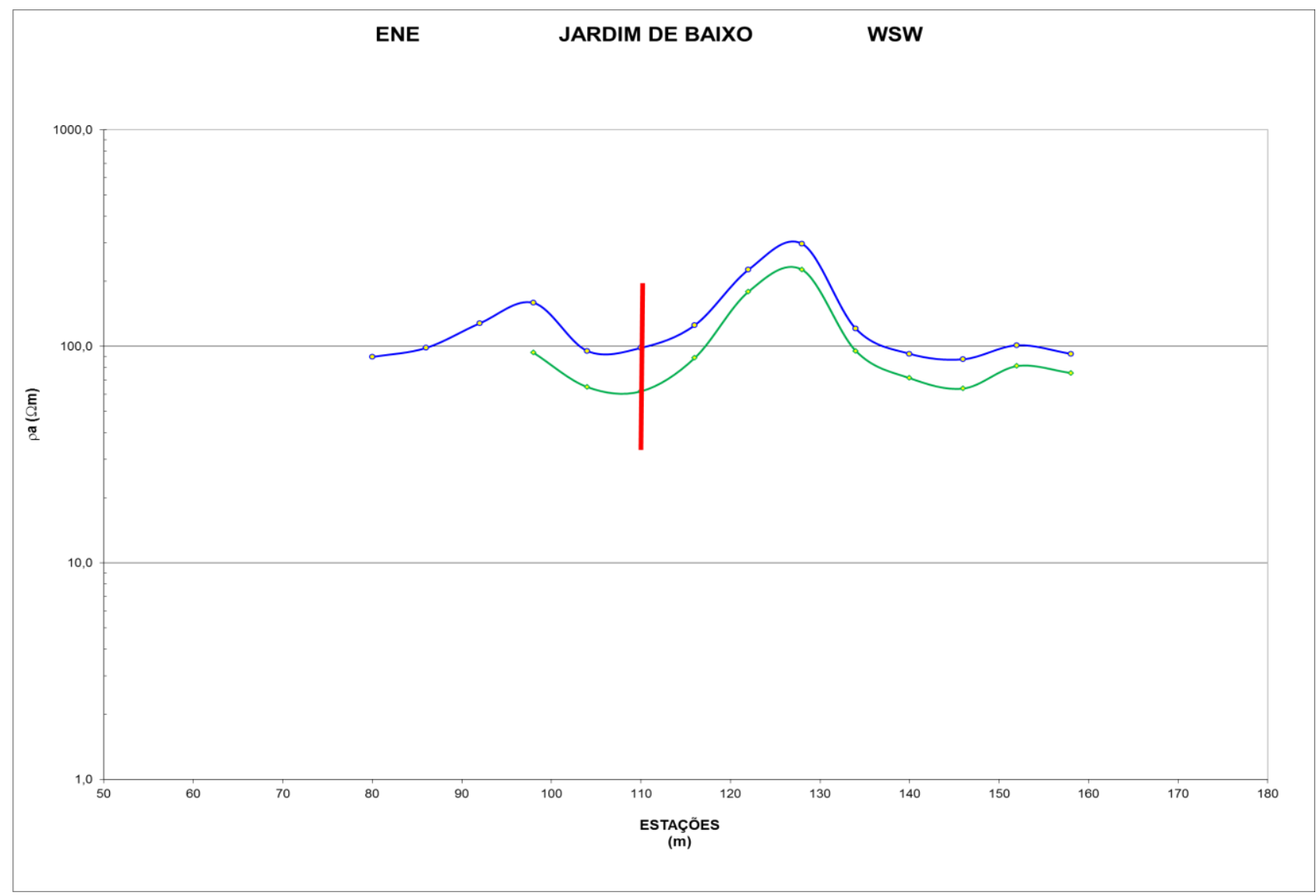

Figura 13: Gráfico com os valores de resistividade plotados. Em verde para AB de 180m e azul para AB de $240 \mathrm{~m}$. Destacando em vermelho o local do poço perfurado.

O perfil geoelétrico de Serragem realizado na direção NE-SW, foi adquirido apenas com $A B$ de $180 \mathrm{~m}$ (Tabela 7), onde o resultado do caminhamento mostrou um ponto condutivo de 203,30hm.m. O local indicado para perfuração está indicado na Figura 14. O poço atingiu profundidade de $60 \mathrm{~m}$ com um revestimento de $25 \mathrm{~m}$ e vazão de $3000 \mathrm{~L} / \mathrm{h}$.

Tabela 7: Dados de resistividade com AB de 240m da localidade Novo Croata, São Gonçalo/CE.

\begin{tabular}{|c|c|c|c|c|c|c|c|c|}
\hline \multicolumn{9}{|c|}{ PERFIL 2} \\
\hline$A B$ & 180 & & & MN & 6 & & $A B / M N$ & $30 \mathrm{a} 40$ \\
\hline PROF= & 45 & & & Altura & 0 & & 30 & \\
\hline ESTAÇÃO & $\mathbf{M}$ & $\mathbf{N}$ & $\mathbf{Y}$ & Leitura X (m) & $\begin{array}{c}\Delta V_{1} \\
(m V)\end{array}$ & $\mathrm{I}_{1}(\mathrm{~mA})$ & $\kappa$ & $\rho_{\mathrm{f}}(\Omega \mathrm{m})$ \\
\hline 1 & 57,00 & 63,00 & 120,00 & 60 & 46,7 & 220 & 3014,4000 & 639,9 \\
\hline 2 & 63,00 & 69,00 & 114,00 & 66 & 28,2 & 220 & 3414,7305 & 437,7 \\
\hline 3 & 69,00 & 75,00 & 108,00 & 72 & 41,1 & 220 & 3756,4062 & 701,8 \\
\hline 4 & 75,00 & 81,00 & 102,00 & 78 & 53,1 & 220 & 4018,1853 & 969,8 \\
\hline 5 & 81,00 & 87,00 & 96,00 & 84 & 60,4 & 220 & 4182,8135 & 1148,4 \\
\hline 6 & 87,00 & 93,00 & 90,00 & 90 & 56,5 & 220 & 4239,0000 & 1088,7 \\
\hline 7 & 93,00 & 99,00 & 84,00 & 96 & 53,6 & 220 & 4182,8135 & 1019,1 \\
\hline 8 & 99,00 & 105,00 & 78,00 & 102 & 64,5 & 220 & 4018,1853 & 1178,1 \\
\hline 9 & 105,00 & 111,00 & 72,00 & 108 & 61,9 & 220 & 3756,4062 & 1056,9 \\
\hline 10 & 111,00 & 117,00 & 66,00 & 114 & 13,1 & 220 & 3414,7305 & 203,3 \\
\hline 11 & 117,00 & 123,00 & 60,00 & 120 & 96,0 & 220 & 3014,4000 & 1315,4 \\
\hline
\end{tabular}




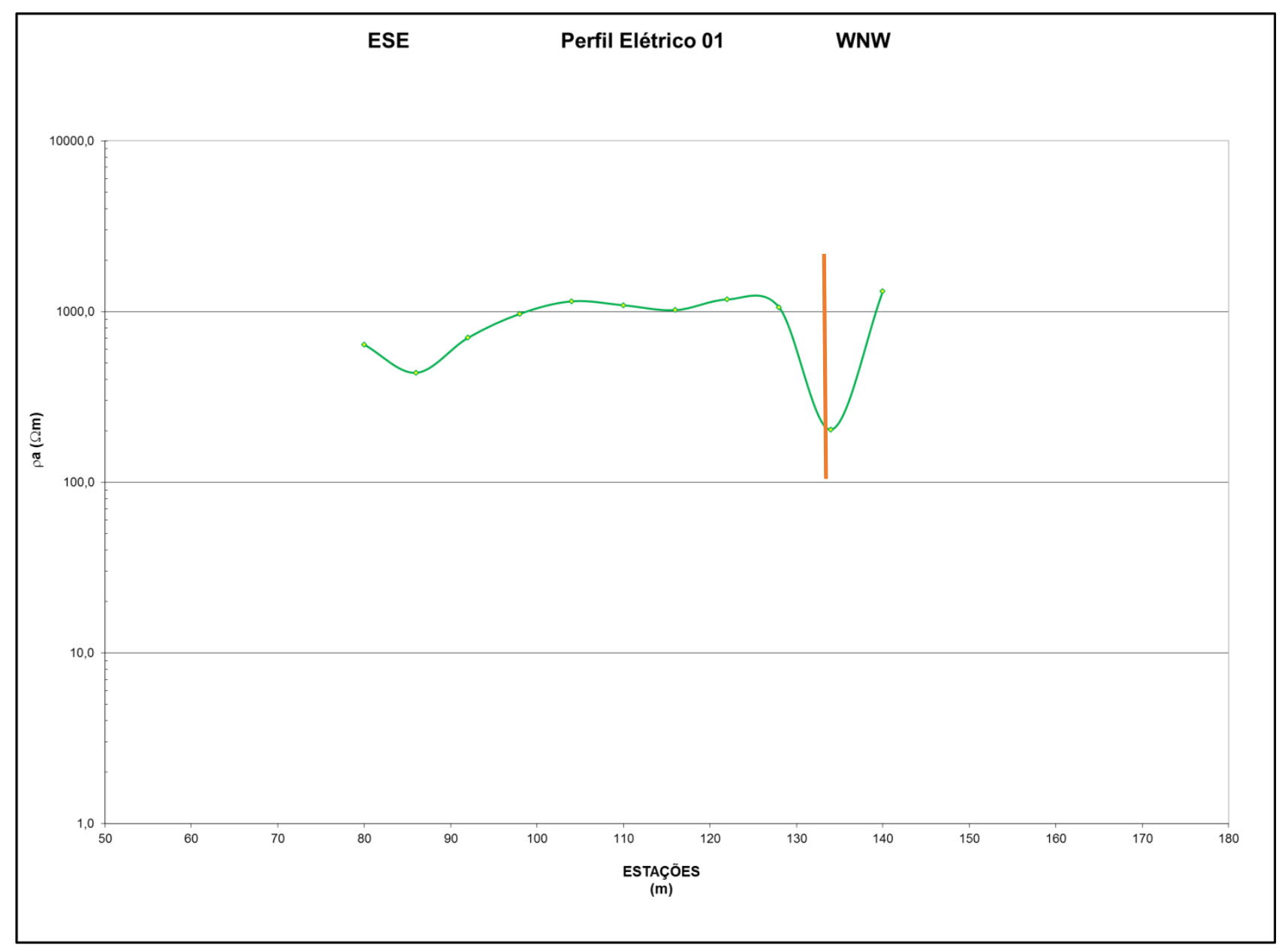

Figura 14: Gráfico com os valores de resistividade plotados. Em verde para AB de 180m. Destacando em vermelho o local do poço perfurado.

Os poços locados da região do município de São Gonçalo são poços que contém água de boa qualidade que variam de 4000 a 10000L/h isso pode ser explicado pelo espeço "pacote" de regolito ou manto de intemperismo que atuam como receptador de precipitação, constituindo uma extensa zona de recarga.

Os perfis geoelétricos de Aratuba, apesar de não mostrarem valores de condutividade tão baixos quanto os observados em São Gonçalo, detectou-se um contraste forte de resistividade lateralmente. Principalmente em Serragem onde a resistividade mostrava valores da ordem de 1000Ohm.m e decaiu para 203Ohm.m, onde justamente por este contraste foi locado o poço.

\section{CONCLUSÕES}

Os resultados obtidos até o momento mostram de modo claro que a análise estrutural bem executada, auxilia de modo sem igual nas locações de poços no cristalino, sendo importantíssimo na tomada de decisão sobre o local e a direção de abertura do arranjo geofísico. Por vezes, perfis 
geoelétricos executados em locais sem identificação estrutural por imagem de satélite, resultaram em resultados negativos, sem contrastes importantes e/ou baixas resistividades.

Os dados geofísicos e resultados dos poços de São Gonçalo e Aratuba reforçam a importância da locação de poços em ambiente cristalino por análise estrutural e levantamento geofísico.

Considerando os dados aqui expostos e a experiência dos autores, o método geofísico se aplica muito bem, de forma rápida e eficaz para locação de poços em ambientes cristalinos. Das mais de 50 locações realizadas no Ceará, o arranjo CE mostrou acerto de cerca de $90 \%$ de poços produtivos, onde os $10 \%$ restante mostram-se fraturas secas ou com vazões de menos que $800 \mathrm{~L} / \mathrm{h}$.

\section{BIBLIOGRAFIA}

BRAGA, A. C. O, 2007. Métodos geofísicos aplicados: módulo hidrogeologia, Apostila da Universidade Estadual Paulista - UNESP/campus Rio Claro. 2007;

GALLAS, J. D. F., 2000. Principais métodos geoelétricos e suas aplicações em prospecção mineral, hidrogeologia, geologia de engenharia e geologia ambiental.174f. Tese (Doutorado em Geociências e Meio Ambiente) Instituto de Geociências e Ciências Exatas, Universidade Estadual Paulista, Rio Claro. 2000;

ORELlANA, E, 1972. Prospeccion Geolectrica en Corriente Continua. Biblioteca Tecnica Philips, Madrid, España: Paraninfo, 523p. 1972;

TELFORD, W. M.; GELDART, L. P.; SHERIFF, R. E., 1990. Applied Geophysics. 2.ed. Cambridge: Cambridge University Press, 744p. 1990;

WARD, S. H., 1990. Resistivity and induced polarization methods.USA. Investigations in Geophysics, no 5. Geotechnical and Environmental Geophysics. Society of Exploration Geophysicists, Ed.Stanley H. Ward, v. I, p. 147-189. 1990; 